\title{
Context-Dependent Modulation of Movement-Related Discharge in the Primate Globus Pallidus
}

\author{
Robert S. Turner ${ }^{1,3,4}$ and Marjorie E. Anderson ${ }^{2,3,4}$ \\ ${ }^{1}$ Department of Neurological Surgery, University of California San Francisco, San Francisco, California 94122, and Departments of ${ }^{2}$ Rehabilitation Medicine \\ and ${ }^{3}$ Physiology and Biophysics and ${ }^{4}$ National Primate Research Center, University of Washington, Seattle, Washington 98195
}

\begin{abstract}
A selective contribution of the basal ganglia (BG) to memory-contingent motor control has long been hypothesized. The importance of memory context remains an open question, however, for the BG skeletomotor circuit. To investigate this question, we studied the perimovement discharge of a carefully selected group of 74 "arm-related" pallidal cells in two rhesus monkeys. The animals performed three tasks designed to dissociate multiple independent aspects of memory-contingent reaching while controlling movement kinematics. The activity of most neurons $(88 \%)$ was influenced strongly by the memory demands of a task (remembering "where" or "when" to move), but the population as a whole showed no systematic preference for memory- or sensory-contingent conditions. The effects of memory context were primarily additive with those of movement kinematics (particularly movement direction). Considered separately, decreases and increases in firing had very different context preferences: decreases were nearly always larger for sensory-triggered movements, whereas increases were enhanced most often under memory-contingent conditions (i.e., self-initiated or self-guided movements). A similar pattern of preferences was found for both pallidal segments. The distinct context-specific enhancements of decreases and increases could not be explained as simple sensory responses or as interactions with preparatory or anticipatory processes present before movement initiation. Rather, they appear related to movement execution under specific contexts. Our results lead to the conclusion that movement facilitatory decreases in internal pallidal (GPi) activity are primarily greater under sensory-triggered conditions. GPi increases and their suppressive effects, perhaps on competing activity in pallidal-recipient centers, have increased prevalence under memory-contingent conditions.
\end{abstract}

Key words: basal ganglia; macaque; reaching; memory contingent; motor control; sensory guidance

\section{Introduction}

The concept that the basal ganglia (BG) contribute preferentially to memory-contingent motor control has a long history (Goldberg, 1985) and ongoing relevance. Selective impairment of movements performed in the absence of external sensory cues and increased reliance on sensory guidance are characteristic symptoms of BG-associated movement disorders (Adamovich et al., 2001). Recording and inactivation studies of the BG oculomotor circuit led Hikosaka and Wurtz (1985) to conclude that the BG are preferentially involved in controlling movements "in the absence of direct sensory control" (depending on memory for "where" to move). Recent studies also suggest a selective involvement of the BG in self-initiated movement (depending on memory for "when" to move) (van Donkelaar et al., 1999, 2000; Cunnington et al., 2002). Other studies have failed to support this hypothesis, however (Mink and Thach, 1991a; Kimura et al., 1992; Inase et al., 1996). Mink and Thach (1991a) found no evi-

\footnotetext{
Received Sept. 29, 2004; revised Jan. 31, 2005; accepted Feb. 1, 2005.

This work was supported by National Institutes of Health Grants RR00166 and NS15017. We thank B. Bedell for excellent technical assistance, Dr. W. Smith for computer programming, and Drs. Izhar Bar-Gad and John Houde for helpful comments on this manuscript.

Correspondence should be addressed to Dr. RobertS. Turner, Department of Neurological Surgery, University of California San Francisco, Box 0520, San Francisco, CA 94143-0520. E-mail: rturner@itsa.ucsf.edu. D0I:10.1523/JNEUROSCI.4036-04.2005

Copyright $\odot 2005$ Society for Neuroscience $\quad 0270-6474 / 05 / 252965-12 \$ 15.00 / 0$
}

dence for a preferential representation of memory-contingent limb movement in the activity of globus pallidal neurons, and neither Mink and Thach (1991c) nor Inase et al. (1996) were able to substantiate the prediction that inactivation of internal globus pallidus (GPi), the primary output nucleus of the BG "somatomotor" circuit, selectively disrupts memory-contingent reaching.

The present study addresses the ongoing controversy by studying the perimovement discharge of "arm-related" pallidal cells during performance of reaching tasks that dissociate multiple aspects of memory-contingent motor control. We report that the activity of individual neurons was influenced strongly by the memory demands of a task (remembering where or when to move), although no systematic preference was found for memory- or sensory-contingent conditions across the population as a whole.

Because of the opposing effects on motor centers of decreases and increases in pallidal firing and of activity in internal and external (GPe) pallidum (Albin et al., 1989; DeLong, 1990), it is important to consider each of these categories separately. Here, we report that context preferences depended on the sign of the change in firing; decreases were nearly always larger when movements were sensory-triggered, whereas increases were enhanced most often under memory-contingent conditions. No differences were found, however, between the two pallidal segments.

The pallidal motor circuit is in a position to influence motor 
execution (Horak and Anderson, 1984a,b; Hoover and Strick, 1993), and activity in that circuit reflects basic parameters of movement such as direction, force, and extent (Georgopoulos et al., 1983; Mitchell et al., 1987; Turner and Anderson, 1997). Context-dependent modulations of pallidal activity, however, have been reported to corrupt the consistent encoding of motor parameters thought necessary for movement planning functions (Brotchie et al., 1991a; Mink and Thach, 1991b). Previously, we showed that pallidal activity often represents movement kinematics (direction and extent) reliably independent of behavioral context (Turner and Anderson, 1997). Here, we expand on that observation by showing for pallidal activity strongly influenced by behavioral context, that the effects of context and movement kinematics are primarily additive. In summary, our results are consistent with the view that the pallidal motor circuit contributes to context-dependent motor control.

\section{Materials and Methods}

Animals and apparatus. The animals, tasks, and recording methods used in this study have been described in detail previously (Turner et al., 1995; Turner and Anderson, 1997). Briefly, two juvenile male Macaca fascicularis monkeys performed three related visuomotor reaching tasks for food rewards. Animals were cared for in accordance with the American Physiological Society Guiding Principles in the Care and Use of Animals (1991). The animals were trained to move the right hand across a digitizing tablet (inclined $5^{\circ}$ from horizontal) to target positions. The animal's hand and forearm were held prone in a light-weight splint on the digitizing tablet ( $\pm 0.6 \mathrm{~mm}$ accuracy; $100 \mathrm{~Hz}$ sampling rate). Lightemitting diodes (LEDs) (Fig. 1), mounted above the digitizing tablet, appeared as virtual images in the workspace via a half-silvered mirror. Eight peripheral LEDs were arranged radially on a $4.8 \mathrm{~cm}$ radius around a central LED. The intensity of the peripheral LEDs and color of the central LED provided feedback as to whether the distal end of the splint was within a target zone $(\sim 2.4 \times 1.2 \mathrm{~cm}$ ellipse $)$ centered on the image of a target LED.

Behavioral tasks. Three behavioral tasks were designed to manipulate the memory requirements of a basic reaching task (Fig. 1). All tasks required an animal first to hold its hand within the central target zone for an initial hold period ["start position hold time" (SPHT)] and then to move its hand to a specified target location within $0.8 \mathrm{~s}$ and to hold its hand at the target location for at least $0.4 \mathrm{~s}$. Food reward was delivered at the end of approximately one-half of the trials performed correctly (chosen pseudorandomly).

The three tasks differed as to the times when a peripheral target was visible and whether a tone signaled the time to initiate movement. Under the "sensory" condition, a peripheral target was lit, and a trigger tone was sounded simultaneously at the end of a variable start position hold time $(1.5,2,2.5$, or $3 \mathrm{~s}$ duration). The animal was required to move its hand to the visible target. The timing of "precued" trials was the same as that of sensory trials except that a peripheral target was lit briefly $(0.5$ and $0.1 \mathrm{~s}$ for animals $\mathrm{A}$ and $\mathrm{B}$ ) at $0.7 \mathrm{~s}$ into the start position hold period. After a variable-duration postinstruction period $(0.7-2.3 \mathrm{~s})$, the trigger tone sounded. The peripheral target was lit again only when the animal's hand entered the appropriate target zone at the end of a memory-guided movement. For "self-timed" trials, one of the peripheral targets was lit continuously, and no trigger tone was presented. The animal was required to hold its hand in the central start zone for at least 0.8 or $1.5 \mathrm{~s}$ (for animals A and B, respectively) and then to move to the peripheral target within $1.5 \mathrm{~s}$. Although the self-timed condition allowed a range of start position hold times approximately equivalent to those of the other two conditions (i.e., 1.5-3 s), animals adopted stereotyped timing when performing self-timed trials (see Fig. $5 C, D$ ). Sensory and precued trials were executed in blocks in which three or six of the targets were presented in pseudorandom order until at least 15 valid trials were performed for each target. Self-timed trials were performed in multiple blocks with one peripheral target per block.

To summarize, the sensory task provided immediate sensory informa-
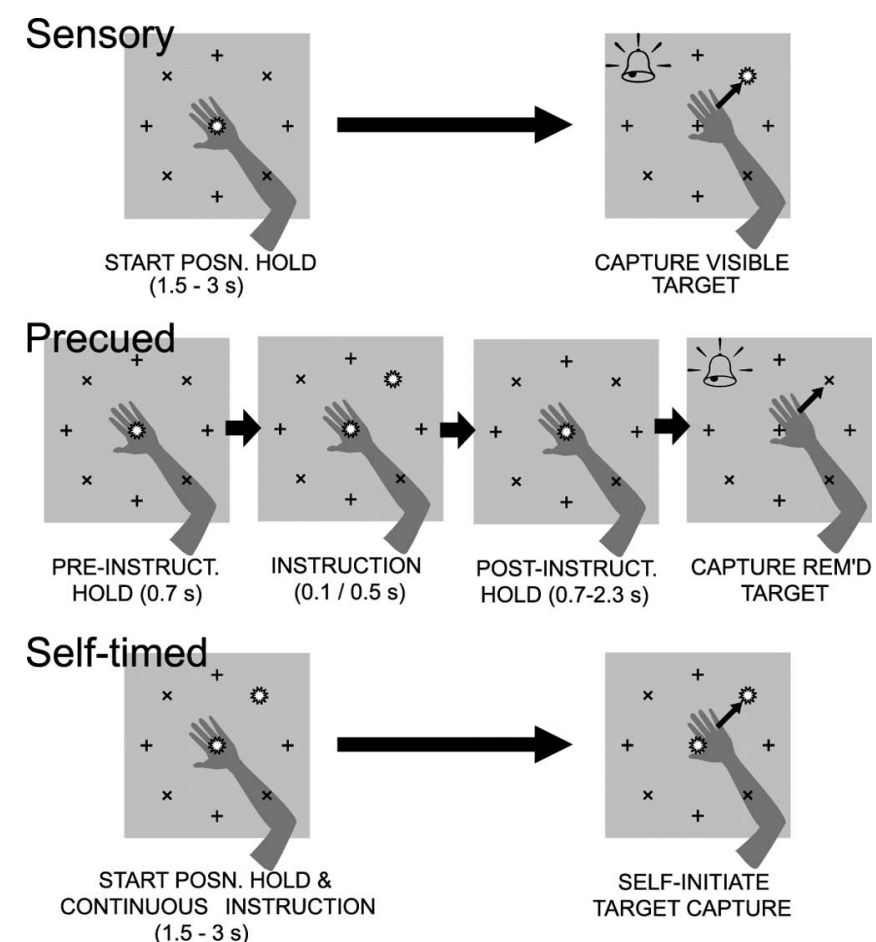

Figure 1. A schematic of behavioral tasks designed to dissociate memory for where and when to move. Animals moved the right arm across a horizontal work surface from a central start position to a radial array of peripheral targets positions $(+)$, indicated at times by the reflected image of a lit LED (\$). Sensory, After a start position (posn.) hold period of random duration $(1.5-3 \mathrm{~s})$, the trigger tone sounded $(\triangle)$, and a peripheral target was lit simultaneously. If the animal met temporal criteria for moving to the visible target $(<0.8 \mathrm{~s})$ and holding that position $(>0.4 \mathrm{~s})$, then juice reward was delivered on a random reward schedule $(\sim 0.5$ probability). Precued, One peripheral LED was lit briefly $(0.1$ or $0.5 \mathrm{~s})$ at $0.7 \mathrm{~s}$ into the start position hold period. At the end of the hold period, only the trigger tone sounded. Reward was delivered as in sensory if the animal moved to the correct remembered target within the same temporal criteria. Self-timed, One peripheral LED was lit continuously from the start of the trial. Reward was delivered if the animal self-initiated movement to the visible target within the allotted time window ( $>1.5$ and $<3$ s from onset of start position hold). No trigger tone was delivered. Instruct., Instruction.

tion concerning where to move (target location) and when to move (trigger tone) at the time of movement initiation. The precued task required that an animal plan where to move based on remembered information, but when to initiate the movement was signaled overtly. The self-timed condition required an animal to plan when to move based on memory (from previous training), but where to move (target location) was visible continuously. The primary factors shared by sensory and precued conditions were the following: (1) delivery of an external trigger tone and (2) execution of sensory-triggered movements in response. The primary task factors shared by precued and self-timed tasks were the following: (1) delivery of early information about target location, (2) the ability to plan movement in advance using such information, and (3) the execution of movement under memorycontingent conditions (i.e., dependent on memory for where or when to move).

Surgery and neuronal recording. Animals were prepared for neuronal recording using aseptic technique under halothane anesthesia. A cylindrical stainless steel recording chamber was affixed to the skull over a craniotomy in stereotaxic coordinates (Szabo and Cowan, 1984) to allow access to the globus pallidus from a $45^{\circ}$ lateral approach (for details, see Turner and Anderson, 1997).

The extracellular discharge of pallidal neurons was recorded with tungsten microelectrodes, amplified and filtered (gain, 5000-20,000; bandpass, $0.5-10 \mathrm{kHz}$ ), and recorded on tape (model 4000; Vetter, Howard, PA). Also recorded on tape were analog signals from the digitizing tablet reflecting $X$ and $Y$ hand position and behavioral logic. Data 
were collected during performance of the behavioral conditions described above and also during movements to targets at different distances from the start position [described previously by Turner and Anderson (1997)]. Most neurons were studied under a subset of the many possible combinations of target locations and behavioral conditions.

After collecting task-related neuronal data, pallidal neurons were tested for responses to a sensorimotor examination. Audio-amplified neuronal activity was monitored while the experimenter held the monkey's arm securely and rotated each joint repetitively. Manual stimulation was also applied to the skin, muscle bellies, and tendons of the arm. The leg, back, tail, neck, and orofacial areas were manipulated in a similar manner.

Histology. The methods used to reconstruct recording locations are described in detail previously (Turner and Anderson, 1997). Briefly, animals were killed by transcardial perfusion (saline followed by $10 \%$ phosphate-buffered formalin). The brains were blocked in place in the stereotaxic coronal plane, removed, fixed in formalin, cryoprotected with sucrose, frozen, cut into $50 \mu \mathrm{m}$ sections, and stained with cresyl violet. The approximate location of each recorded neuron was estimated by comparing the location of a penetration in the chamber, the position of the neuron along the recording penetration relative to electrophysiologically identified borders, and the position of marking lesions made in the same and/or adjacent penetrations during final recording sessions.

Data analysis. The recorded data were digitized off-line. The action potentials were time/amplitude discriminated (DIS-1; BAK Electronics, Germantown, MD), converted to acceptance pulses, and digitized at 2 $\mathrm{kHz}$ along with analog signals reflecting $X$ and $Y$ hand position and behavioral logic (ComputerScope ISC-67; RC Electronics, Santa Barbara, CA). Hand position signals were filtered and differentiated using smoothing cubic splines, and tangential velocity was calculated. Movement initiation $(\mathrm{M})$, peak tangential velocity, and movement termination (E) were detected automatically using position, tangential velocity, and duration criteria. Reaction time (RT), movement time (MT), movement extent, and peak velocity ( $\mathrm{PkVel})$ were computed. SPHT was defined under all three conditions as the time interval between initial positioning of the hand at the start position and the onset of movement to capture a peripheral target

All quantitative analyses of unit discharge were performed on values extracted from spike density functions (SDFs). SDFs were constructed for each behavioral trial as the sum of Gaussian functions (unit area, 20 $\mathrm{ms} \sigma$ ) centered on the times of each discriminated action potential (for method, see Szucs, 1998). Perimovement changes in discharge were detected in average SDFs constructed for each task and target combination (Turner and Anderson, 1997). Within each average, the SDF during a search period (300 ms before M until $200 \mathrm{~ms}$ after M) was tested for deviations from control SDF values (from a $500 \mathrm{~ms}$ epoch ending $300 \mathrm{~ms}$ before $\mathrm{M}$ ). A perimovement change was defined as a deviation above or below the control rate that exceeded statistical threshold ( $t$ test; one sample vs control period mean; $p<0.02$ ) for at least $20 \mathrm{~ms}$. To detect biphasic changes, the same criteria were applied a second time after the mean SDF returned to baseline after the initial change. If a perimovement decrease was detected for any task and target, single trial measures of that decrease were extracted for all tasks and targets, being composed of minima from the search periods of all single trial SDFs. Likewise, if any increase in discharge was detected, SDF maxima were extracted as single trial measures of the increase.

A nonparametric "randomization test" (Lurito et al., 1991) was used to test for unimodal directional modulations in discharge, and the mean direction of that modulation, $\bar{\theta}$, was taken as a preferred direction of the change (Mardia, 1972). The onset times of single trial changes in discharge were assessed for temporal correlations (i.e., time "locking") with the times of trigger presentation ( $\mathrm{T}$ ) or $\mathrm{M}$ as described by Turner and Anderson (1997). Such time locking has been considered evidence for an underlying functional linkage between the behavioral event and the neural discharge (cf. Commenges and Seal, 1985; Hanes et al., 1995).

Classification of condition effects. A two-way ANOVA was used to test whether the perimovement discharge of a cell differed between behavioral conditions and whether this effect interacted with the direction of movement. Changes that differed significantly between conditions $(p<$
0.05 ; condition main effect or condition $\times$ direction interaction) were submitted to the following classification analysis.

The functional significance of a condition effect depends on how differences in discharge are distributed across behavioral conditions. "Context preference indices" (CPIs) were computed to address the central question whether perimovement changes in pallidal discharge were consistently larger (i.e., enhanced) under one or two of the three behavioral conditions. A consistent enhancement under one behavioral condition (i.e., "condition-specific" enhancement) can be taken as evidence that pallidal neurons preferentially encode information about an aspect of the task unique to that condition. Equal enhancement under two of the three conditions would suggest the enhancement was related to a factor shared by the two conditions (i.e., a "factor-specific" enhancement). To measure whether pallidal discharge showed condition- or factor-specific enhancements, we performed three pairwise comparisons according to the following equations:

$$
\begin{aligned}
\mathrm{CPI}_{\mathrm{SvP}} & =\sum_{d=1}^{n}\left[w_{d} \times\left(\left|P_{d}\right|-\left|S_{d}\right|\right) /\left|P_{d}-S_{d}\right|\right] / \sum_{d=1}^{n} w_{d} \\
\mathrm{CPI}_{\mathrm{SvT}} & =\sum_{d=1}^{n}\left[w_{d} \times\left(\left|T_{d}\right|-\left|S_{d}\right|\right) /\left|T_{d}-S_{d}\right|\right] / \sum_{d=1}^{n} w_{d} \\
\mathrm{CPI}_{\mathrm{PvT}} & =\sum_{d=1}^{n}\left[w_{d} \times\left(\left|T_{d}\right|-\left|P_{d}\right|\right) /\left|T_{d}-P_{d}\right|\right] / \sum_{d=1}^{n} w_{d}
\end{aligned}
$$

Taking the sensory versus precued comparison as an example, the preference index $\left(\mathrm{CPI}_{\mathrm{SvP}}\right)$ was determined by computing the sign of the difference in discharge under sensory $\left(S_{d}\right)$ and precued $\left(P_{d}\right)$ conditions for each target direction $(d)$. Absolute values $\left|S_{d}\right|$ and $\left|P_{d}\right|$ ensured that both increases and decreases in discharge would yield -1 if the change was larger for sensory and +1 for the precued condition. A weighted average across directions yielded one value, $\mathrm{CPI}_{\mathrm{SvP}}$, which reflected the preference of a change in discharge for sensory versus precued conditions (respectively, -1 and +1 in the extreme). The weighting factors $\left(w_{d}\right)$ were proportional to the maximal change in activity for that direction (i.e., across conditions) relative to the maximal change across directions and conditions. By including preference information from the nonpreferred directions of a neuron, a CPI takes into account the broad directional tuning curves described for these neurons (Turner and Anderson, 1997) and measures the degree to which a condition preference was consistent across directions. Therefore, $w_{d}$ allowed directions with perimovement discharge of similar magnitude to contribute similarly to a CPI, whereas directions with little perimovement discharge under either condition contributed little. Preference indices for sensory versus selftimed conditions $\left(\mathrm{CPI}_{\mathrm{SvT}}\right)$ and precued versus self-timed conditions $\left(\mathrm{CPI}_{\mathrm{PvT}}\right)$ were computed similarly for all perimovement activity influenced by behavioral condition as determined by the initial two-way ANOVA (see Fig. 4, top).

The three-way relationship of unit discharge to the three behavioral conditions was determined using the three CPIs. This analysis allowed us to address relational questions such as the following: does discharge that prefers self-timed over the sensory condition $\left(\mathrm{CPI}_{\mathrm{SvT}}>0\right)$ also prefer self-timed when compared with the precued condition $\left(\mathrm{CPI}_{\mathrm{PvT}}>0\right)$ ? Because of the properties of the above equations, the three CPI dimensions can be projected onto an equilateral "endowment triangle" (Leamer, 1987) with no loss of information. The position of points within this triangle indicated whether a change in discharge showed consistent preferences for one or two of the three behavioral conditions (Fig. 4 , bottom). Positions close to one vertex of the triangle indicated a condition-specific enhancement in discharge, whereas a position halfway between two vertices indicated a factor-specific enhancement. The central location and dispersion of points within the triangle was estimated by the position, size, and orientation of a confidence ellipse estimated to enclose the central $50 \%$ of points (Johnson and Wichern, 1982).

Interacting effects of behavioral condition and task performance. Pallidal 
Table 1. Prevalence of condition effects

\begin{tabular}{lllr}
\hline & \multicolumn{3}{l}{ Changes in discharge } \\
\cline { 2 - 4 } & Cells $(n=74)$ & Increases $(n=68)$ & Decreases $(n=54)$ \\
\hline GPe & 50 of $57(88 \%)$ & 40 of $52(77 \%)$ & 31 of $46(67 \%)$ \\
GPi & 15 of $17(88 \%)$ & 13 of $16(81 \%)$ & 6 of $8(75 \%)$ \\
Total & 65 of $74(88 \%)$ & 53 of $68(78 \%)$ & 37 of $54(69 \%)$ \\
\hline
\end{tabular}

activity is often correlated with one or more parameters of task performance (e.g., movement speed or direction), and it is important to understand how the effects of behavioral condition interact with these parametric relationships. It is also important to consider whether apparent condition-related differences in neuronal activity were actually a result of underlying differences in task performance. These questions were addressed using analyses of covariance (ANCOVAs) of trial-by-trial measures of pallidal activity selected from the direction of movement for which a condition effect was maximal. Four separate two-way ANCOVAs were performed using behavioral condition as the group factor (two or three levels) and a measure of task performance (RT, MT, $\mathrm{PkVel}$, or SPHT) as the covariate. Only sensory and precued conditions were used in the RT ANCOVA.

A separate analysis investigated the influence of behavioral condition on the directionality of pallidal discharge. Taking into account the unique properties of circular relationships (Fisher, 1993), regressions determined the total variance in neuronal activity across movement directions and behavioral conditions explained by the following three models:

(1) Additive effects: condition effects were modeled as a global alteration of response magnitude independent of target direction (i.e., as a main effect of condition in the initial two-way ANOVA; see Fig. 7A).
(2) Directional gain: based on observations that pallidal directionality tends to remain constant across behavioral conditions (Turner and Anderson, 1997), we investigated how well modulations in the magnitude of a common directional tuning curve (i.e., of constant preferred direction) accounted for condition-related differences in neuronal discharge (see Fig. 7C). Here, a cosine directionality function [i.e., $y=a+$ $g \times \cos (\theta-\bar{\theta})]$ was used to model the relationship between movement direction $(\theta)$ and mean discharge rate across conditions $(y)$ (Georgopoulos et al., 1982). The gain $(g)$ and offset $(a)$ of the function were then scaled to fit data from each behavioral condition separately, according to least-squares criteria, while holding constant the preferred direction $(\bar{\theta})$ of the function.

(3) Directional shift: based on reports that the directionality of pallidal discharge may be inconsistent under different behavioral conditions (Brotchie et al., 1991a; Mink and Thach, 1991b), we investigated whether condition-by-direction interactions could be explained as shifts in $\bar{\theta}$ and $a$ of a cosine function of constant $g$ (see Fig. 7E). Preferred directions were computed separately for each behavioral condition as the mean resultant according to Fisher (1993). Cosine functions $[y=a+g \times$ $\cos (\theta-\bar{\theta})]$ were fit to data from each condition independently according to least-squares criteria with the constraint that all functions share the same gain.

The strength of these three models was evaluated with respect to the fractional variance in neuronal discharge that each model accounted for.

\section{Results}

\section{Database}

The activity of 74 neurons was sampled from the proximal arm representation of the posterior ventral globus pallidus [i.e., the pallidal "skeletomotor" territory (Hamada et al., 1990)]. All 74 neurons had high tonic discharge rates ( $>50$ spikes/s) and peri-

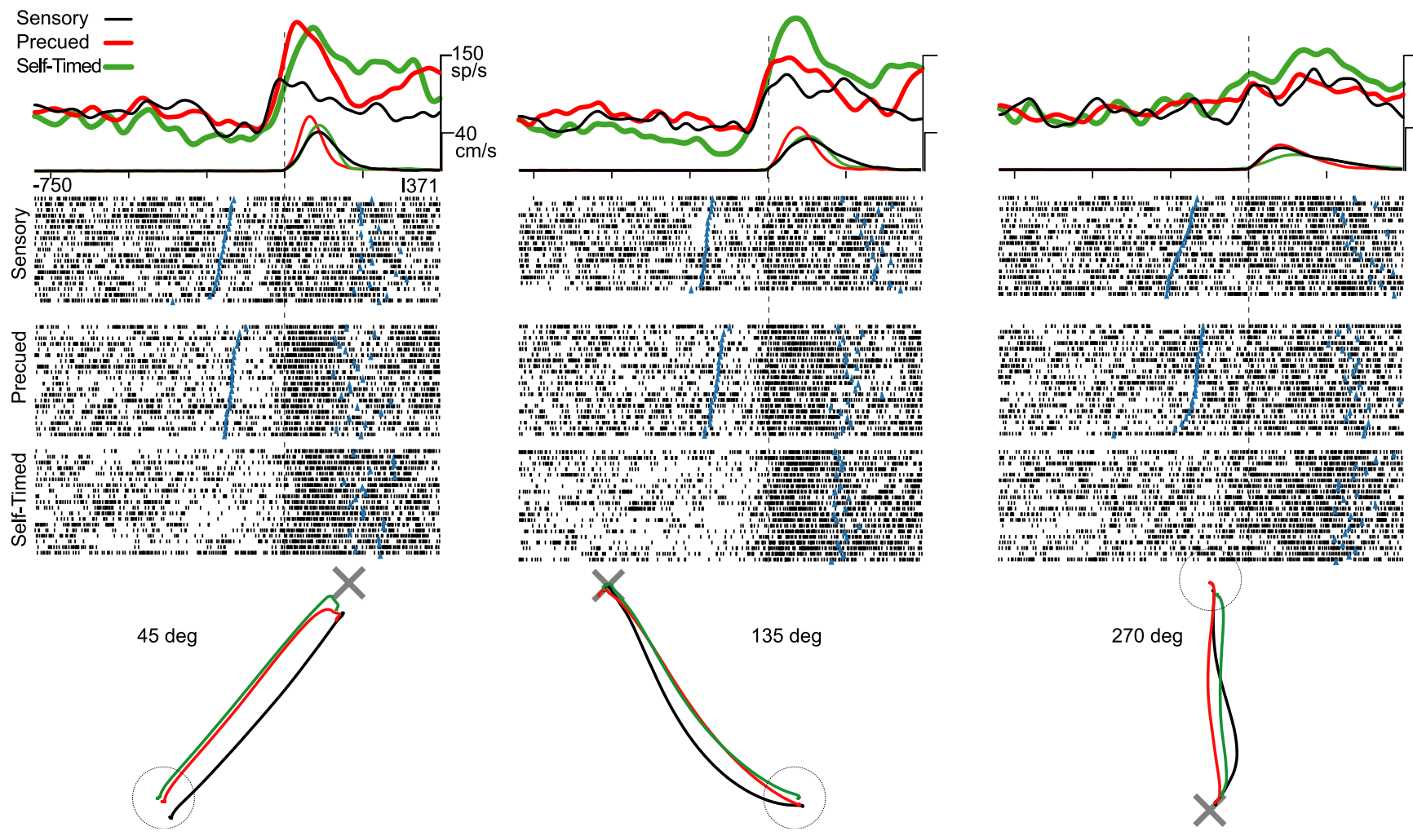

Figure 2. Effects of behavioral condition on the activity of a cell in GPe. A small increase in discharge that began immediately before movement onset under the sensory condition was markedly enhanced under precued and self-timed conditions during movements to targets at $45^{\circ}$ (left) and $135^{\circ}$ (middle; $p<0.005$; condition main effect and condition $\times$ direction interaction; $F$ test). Perimovement discharge and kinematic variables are plotted for three directions of movement (left, middle, and right; 45,135 , and $270^{\circ}$, respectively) under three behavioral conditions (indicated by line color and thickness). Mean SDFs and tangential velocities (top) and raster diagrams (trials sorted by the trigger-to-movement interval; middle) are aligned on the time of movement onset (vertical dashed lines). Mean movement trajectories (bottom) are plotted relative to effective positions of center $(O)$ and peripheral $(X)$ targets. Blue triangles in the raster diagrams indicate times of either target appearance or movement termination. 

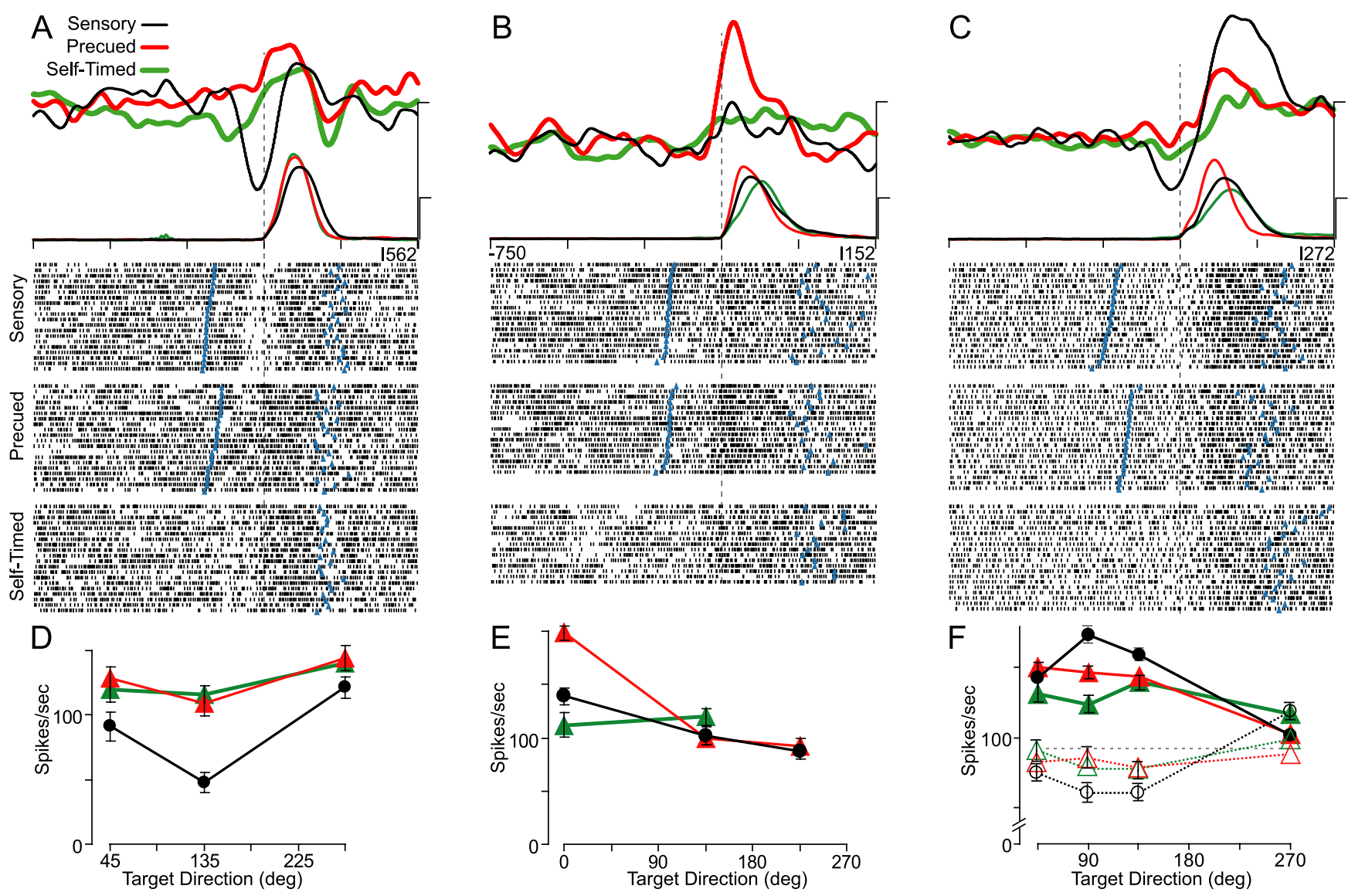

Figure 3. Examples of the varying effects of context on perimovement pallidal activity. $A, A$ premovement decrease in activity selective for the sensory condition (condition $\times$ direction interaction; $p<0.005 ; F$ test) is shown. $\boldsymbol{B}$, An increase in firing selective for the precued condition is shown. Subtle increases were observed for movements in the same direction under sensory and self-timed conditions (condition $\times$ direction interaction; $p<0.005 ; F$ test). C, A biphasic change in firing (decrease/increase), both components of which were enhanced under the sensory condition (for both increase and decrease; condition main effect and condition $\times$ direction interaction; $p<0.005 ; F$ test), is shown. Calibration bars for SDFs and tangential velocity, $100 \mathrm{spikes} / \mathrm{s}$ and $40 \mathrm{~cm} / \mathrm{s}$, respectively. $\mathbf{D}-\boldsymbol{F}$, Preferred directions were similar across conditions. Other conventions follow those of Figure 2. Error bars represent SEM.

movement changes in activity that were modulated by the direction of movement (Turner and Anderson, 1997). These neurons either responded to experimenter-imposed manipulations of the proximal arm $(n=62)$ or were encountered within $0.5 \mathrm{~mm}$ of such responsive neurons $(n=12)$. Histological reconstruction placed these neurons in the caudolateral portions of GPe (57 cells) or GPi (17 cells) (Turner and Anderson, 1997). The discharge of all 74 neurons was studied during movements to targets in at least three directions under sensory and precued conditions. Fifty-five of the neurons were also studied under the self-timed condition. Within this select population, movement-related increases were detected slightly more often than decreases $(56 \%$ of all changes) (Table 1). Biphasic changes were detected in more than one-half of the cells ( 48 of $74 ; 68 \%$ ), leading to a total of 122 perimovement changes in discharge studied for effects of behavioral condition (Table 1).

\section{Pallidal perimovement activity is strongly influenced by behavioral context}

The perimovement activity of many cells differed markedly between conditions. Figure 2 shows an example in which an increase in firing was much larger under precued and self-timed conditions during movements to targets at 45 and $135^{\circ}$. The increase had a nominal directionality under the sensory condition ( $p>0.05$; randomization test), whereas it was highly directional under precued and self-timed conditions (both $p<0.001$ ). Al- though the peak-to-peak directional modulation in discharge differed substantially between conditions, the preferred directions were all within $10^{\circ}$ of each other. In contrast to the large differences in neuronal discharge between conditions, movement trajectories (Fig. 2, bottom) and tangential velocities (Fig. 2, top) differed only slightly. Whether differences in kinematics may account for context-related differences in discharge is addressed quantitatively in a separate section below.

The perimovement activity of most pallidal cells differed significantly between conditions ( 65 of 74 cells; $88 \%$; condition main effect or condition $\times$ direction interaction; $p<0.05 ; F$ test) (Table 1). Effects of behavioral condition were equally common in the two pallidal segments $\left(\chi^{2}=2.9 ; p>0.2\right)$ and for decreases and increases in discharge $\left(\chi^{2}=2.6 ; p>0.2\right)$. The influence of behavioral condition was most often to modulate the magnitude of a perimovement change that was present under all conditions. Considering each change in discharge as a separate case, condition-related modulations represented a mean $45 \%( \pm 16 \%$ $\mathrm{SD}$ ) of the maximal perimovement change from baseline. In only 6 of 90 cases did a condition effect comprise $>70 \%$ of the maximum perimovement change. Expressed as a fraction of the maximum perimovement change, the magnitude of condition effects did not differ between cells recorded in GPe and GPi (45.3 vs $45.5 \% ; t=0.06)$ nor did it differ between decreases and increases in discharge ( 46.0 vs $44.4 \% ; t=0.27$ ).

The specific effects of context differed between cells (Fig. 3). 
Decreases in discharge were frequently largest under the sensory condition (Fig. $3 A, D$ ) and/or the precued condition (data not shown). Increases, in contrast, tended to be larger under selftimed and/or precued conditions (Figs. 2, 3B). Exceptions to this trend were observed, however (Fig. $3 C$ ). For all three examples shown in Figure 3, the magnitude of behavioral condition effects differed depending on the direction of movement (Fig. 3D-F). Across the sample as a whole, responses showed no systematic bias for any one condition. All three condition preference indices (see Materials and Methods) were distributed uniformly around zero $\left(p>0.2,0.8\right.$, and 0.4 for nonzero distributions of $\mathrm{CPI}_{\mathrm{SvP}}$, $\mathrm{CPI}_{\mathrm{SvT}}$, and $\mathrm{CPI}_{\mathrm{PvT}}$, respectively; Wilcoxon signed rank test).

\section{Decreases and increases in discharge prefer different behavioral contexts}

The central question of this study was whether perimovement activity in the pallidum showed a preference for a specific behavioral context. Selective enhancement of activity under one behavioral condition would imply that the pallidum encodes information about task factors unique to that condition. Similarly, approximately equal enhancements under two of the three conditions could be taken as evidence for encoding of factors shared by those two conditions. Inspection of data from individual neurons suggested that decreases and increases in discharge might prefer different behavioral contexts (Figs. 2, 3).

Examination of CPIs confirmed that decreases were enhanced most often under sensory and/or precued conditions (i.e., under sensory-triggered conditions) (Fig. 4, left). The CPIs comparing sensory versus self-timed and precued versus self-timed conditions demonstrated strong preferences for the sensory and precued conditions, respectively (Fig. 4C,E, statistics noted in figure). The CPI comparing sensory versus precued, however, showed only a slight bias for the sensory condition (Fig. 4A). The three-way distribution of these CPI results (Fig. $4 G$ ) further illustrated the systematic preference of decreases for sensory and precued conditions, conditions under which a trigger tone signaled the time for movement initiation. An ellipse estimated to enclose the central $50 \%$ of points lay next to the sensory-to-precued leg of the triangle, with the long axis of the ellipse oriented parallel to that leg. For both GPe and GPi neurons, the mean CPI for decreases was located approximately halfway between the sensory and precued vertices of the endowment triangle (Fig. $4 G$, + and $\times$, respectively).

Increases tended to be of greater magnitude under self-timed and/or precued conditions (i.e., under memory-contingent conditions) (Fig. 4, right column), although this preference was not as consistent across the population as was that of decreases. CPIs comparing sensory versus precued and sensory versus self-timed conditions demonstrated significant preferences for precued and self-timed conditions, respectively (Fig. $4 B, D$ ). The comparison of precued versus self-timed conditions showed no significant bias (Fig. 4F). The three-way distribution reinforced the view that increases had a systematic preference for precued and selftimed conditions (Fig. 4H). Although CPIs for individual increases were distributed widely across the endowment triangle, the central $50 \%$ of points were circumscribed by an ellipse lying close to and aligned with the precued-to-self-timed leg of the triangle. The mean CPIs of GPe and GPi neurons were similar (Fig. $4 H,+$ and $\times$, respectively), showing approximately equal preference for precued and self-timed conditions. Reinforcing the view that similar context preferences were found in the two pallidal segments, no significant differences were found in the distributions of CPIs for responses sampled from GPe and GPi
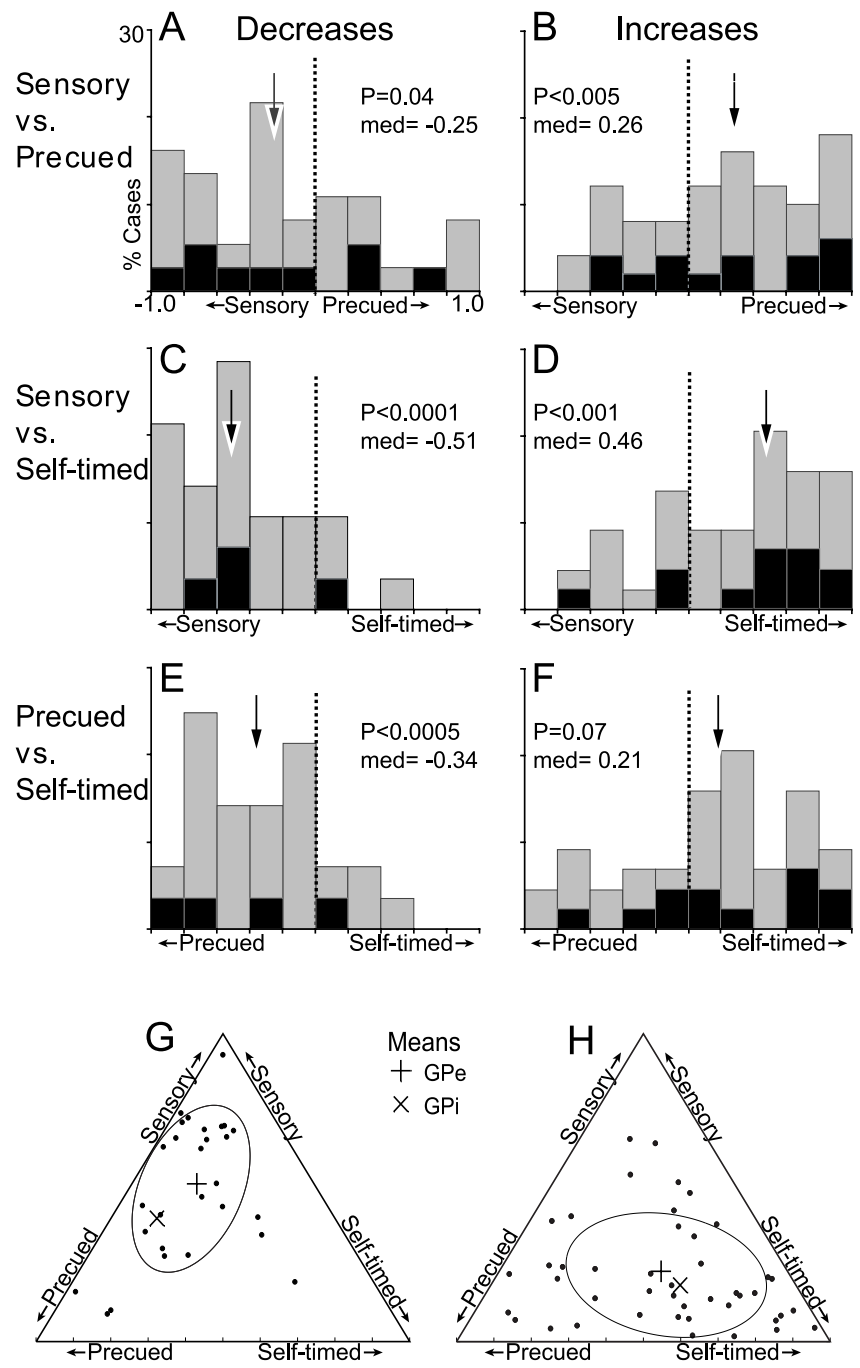

Figure 4. Distributions of CPIs for perimovement decreases and increases in firing. The majority of decreases were of greater magnitude under (i.e., preferred) sensory and/or precued conditions (left), whereas increases preferred self-timed and/or precued conditions (right). $\boldsymbol{A}-\boldsymbol{F}$, For each change in activity affected by condition, three CPIs summarized the pairwise preference for sensory versus precued $(\boldsymbol{A}, \boldsymbol{B})$, sensory versus self-timed $(\boldsymbol{C}, \boldsymbol{D})$, and precued versus self-timed $(\boldsymbol{E}, \boldsymbol{F})$. Decreases rarely preferred the self-timed condition $(\boldsymbol{C}, \boldsymbol{E})$ but showed only a slight bias for the sensory condition in the sensory versus precued comparison $(\boldsymbol{A})$. Increases, in contrast, seldom preferred the sensory condition $(\boldsymbol{B}, \boldsymbol{D})$ but showed no systematic bias in the comparison of precued versus self-timed conditions $(\boldsymbol{F})$. For each subpanel, statistics reflect the Wilcoxon signed rank test for median $C P I=0$ (i.e., probability that there was no bias in the distribution) and the median (med; arrows). Gray and black shading of columns indicates distributions for data sampled from GPe and GPi, respectively. $\boldsymbol{G}, \boldsymbol{H}$, Endowment triangles summarize the three-way condition preferences of decreases and increases in firing ( $G$ and $\boldsymbol{H}$, respectively). For each change in firing, the three pairwise (PIs determined the position of a point $(\bullet)$ projected onto an equilateral triangle. The proximity of a point to one of the vertices of the triangle indicated the degree to which a change in firing preferred the sensory (top), precued (left bottom), or self-timed (right bottom) condition. Positions halfway between two vertices indicated equal preference for the two conditions represented by those vertices. Most decreases showed approximately equal preference for sensory and precued conditions $(\boldsymbol{G})$, whereas increases were most often largest under precued and self-timed conditions $(\boldsymbol{H})$. Ellipses estimated to enclose the central $50 \%$ of points illustrate the central location and dispersion of points. Mean preferences plotted separately for GPe and GPi cells ( + and $\times$, respectively) illustrate that similar condition preferences were found for the two pallidal segments.

( $p>0.1$; comparing GPe vs GPi distributions of $\mathrm{CPI}_{\mathrm{SvP}}, \mathrm{CPI}_{\mathrm{SvT}}$, and $\mathrm{CPI}_{\mathrm{PvT}}$; Komolgorov-Smirnov two-sample test) (Fig. 4A-F, gray and black columns, respectively).

What specific aspects of the behavioral tasks (i.e., what task 

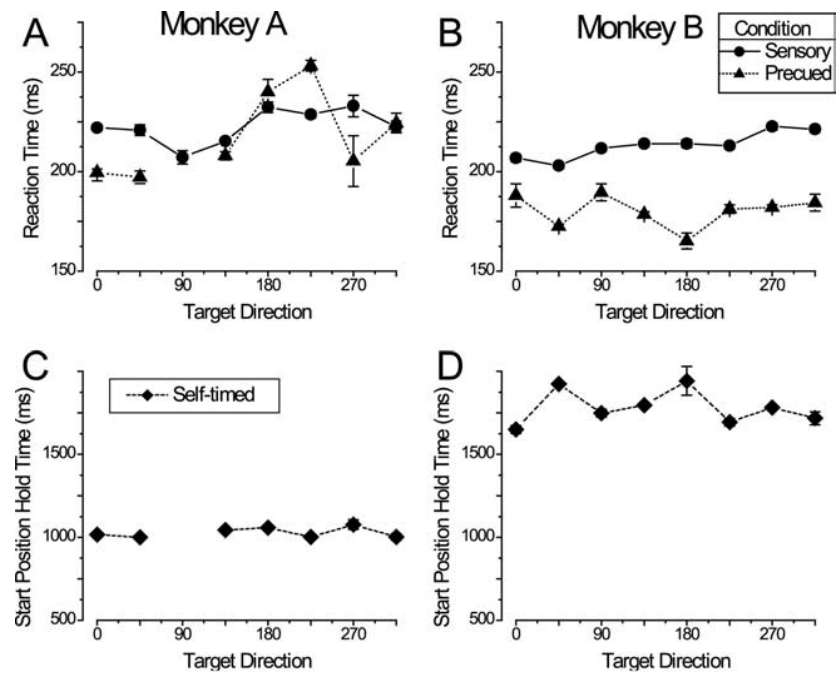

Figure 5. $\quad \boldsymbol{A}, \boldsymbol{B}, \mathrm{RT}$ differed between sensory and precued conditions in both animals. Data were summarized across 23 and 35 representative days of data collection in monkeys $A$ and $B$, respectively. Mean RTs ( \pm SEM) are plotted for individual target directions. For monkey $A$, condition-related differences in RT depended on the direction of movement ( $p<0.001$; condition $\times$ direction interaction; $F$ test). For monkey $B$, RTs were consistently shorter under the precued condition ( $p<0.0001$; condition main effect; $F$ test). C, D, SPHTs had low variability under the self-timed condition and were relatively consistent across directions. The required SPHT duration was $0.8 \mathrm{~s}$ for monkey $A$ and $1.5 \mathrm{~s}$ for monkey $\mathrm{B}$.

factors) accounted for the condition-related enhancements in activity? The preferential enhancement of decreases could be explained potentially by the following two factors that were shared by sensory and precued conditions: (1) delivery of a trigger tone and (2) execution of a sensory-triggered movement. A close linkage to the trigger tone was discounted, however, by a dearth of evidence that decreases were temporally correlated with tone presentation. Only one decrease had onset times that were timelocked to the trigger tone $(6 \% ; n=1$ of 17$)$ in contrast with the relative abundance of decreases that were movement-locked $(53 \% ; n=9$ of 17$)$ or temporally indeterminate $(41 \%)$. The abundance of movement-locked decreases is consistent with the view that decreases were preferentially involved in movement control under sensory-triggered conditions.

The preferential enhancement of increases could potentially be explained by the following three factors shared by self-timed and precued conditions: (1) availability of early information about target location, (2) the planning of movement in advance using such information, and (3) the general memory-contingent nature of those tasks (i.e., dependent on memory for where or when to move). Explanation 1 or 2 would be supported if the presence or sign of preparatory activity before movement predicted the enhancement of perimovement increases. We found no consistent correlation across cells, however, between mean firing rates during the preparatory period (800-300 ms before

Table 2. Prevalence of ANCOVA effects

\begin{tabular}{|c|c|c|c|c|c|}
\hline & \multicolumn{2}{|c|}{ Main effects } & \multirow{2}{*}{$\begin{array}{l}\text { Interaction } \\
\text { condition } \times \text { factor }\end{array}$} & \multirow[b]{2}{*}{ Any effect of factor } & \multirow[b]{2}{*}{ Task factor only } \\
\hline & Condition & Task factor & & & \\
\hline $\mathrm{RT}(n=87)$ & $52(60 \%)$ & $5(6 \%)$ & $3(3 \%)$ & $7(8 \%)$ & $1(1 \%)$ \\
\hline $\mathrm{MT}(n=87)$ & $76(87 \%)$ & $5(6 \%)$ & $9(10 \%)$ & $13(15 \%)$ & $1(1 \%)$ \\
\hline Velocity $(n=87)$ & $69(79 \%)$ & $6(7 \%)$ & $7(8 \%)$ & $13(15 \%)$ & $1(1 \%)$ \\
\hline Hold time $(n=87)$ & $73(84 \%)$ & $10(11 \%)$ & $2(2 \%)$ & $12(14 \%)$ & $0(0 \%)$ \\
\hline
\end{tabular}

movement initiation) and condition-related enhancements of perimovement activity $\left(p>0.2 ; R^{2}=0.02\right.$ and 0.04 for correlations of increases under precued and self-triggered conditions, respectively). Thus, only the general memory-contingent nature of precued and self-triggered movements (factor 3, above) remained a possible explanation for the enhancement of increases under those conditions.

\section{Condition effects are rarely related to differences in task performance}

It was important to consider the possibility that the apparent preferences of pallidal discharge for specific behavioral conditions were related to underlying differences in task performance. This possibility was especially pertinent given the abundant evidence that pallidal activity is correlated with task parameters (Georgopoulos et al., 1983; Anderson and Turner, 1991; Turner and Anderson, 1997; Turner et al., 2003), combined with our previous observations that temporal aspects of task performance differed consistently between conditions (Turner et al., 1995) (see below). To summarize those differences in performance, monkey B generally moved faster under the precued condition (i.e., peak velocities were higher and movement durations were shorter) than under sensory and self-timed conditions (Fig. 3A-C, tangential velocities) [Turner et al. (1995), their Fig. 5]. For monkey A, movement velocities and durations differed across conditions and movement directions in a complex pattern difficult to summarize. Spatial characteristics of task performance (i.e., movement extent, movement curvature, and movement accuracy) did not differ between conditions for either animal (Turner et al., 1995). RTs also differed between sensory and precued conditions (Fig. 5A,B). Monkey $B$ showed consistently shorter RTs under the precued condition (Fig. 5B, statistics in figure legend). For monkey A, the difference in RTs between conditions varied across directions of movement (Fig. 5A). [Data for these analyses were taken from the same behavioral trials as used for the kinematic analyses reported by Turner et al. (1995).] Under the self-timed condition, start position hold times (i.e., the self-timed interval before self-initiating a reach) had low variability and relatively consistent values across movement directions. SPHTs for sensory and precued conditions varied randomly from trial to trial as determined by the task computer.

Analysis of covariance, however, showed that differences in task performance accounted for the neuronal effects of behavioral condition in only $3 \%$ of the cases examined ( 3 of 87 ) (Table 2 , task factor only). Four separate two-way ANCOVAs were performed to assess the interacting effects on neuronal discharge of a task parameter (RT, MT, PkVel, or SPHT) and behavioral condition. For the three cells with significant ANCOVAs, correlations of discharge with RT, MT, or PkVel (one case each) accounted for differences in discharge between conditions. Figure $6 \mathrm{~A}$ shows an example in which a monotonic relationship between firing rate and $\mathrm{PkVel}$ (black regression line) was consistent across sensory and precued conditions (statistics in figure legend). Combined with the fact that movements were faster, on average, under the precued condition, the parametric relationship to velocity resulted in a higher mean discharge under the precued condition (Fig. 6A, large symbols). The great majority of neuronal effects of condition, however, was not explained by differences in task performance. 

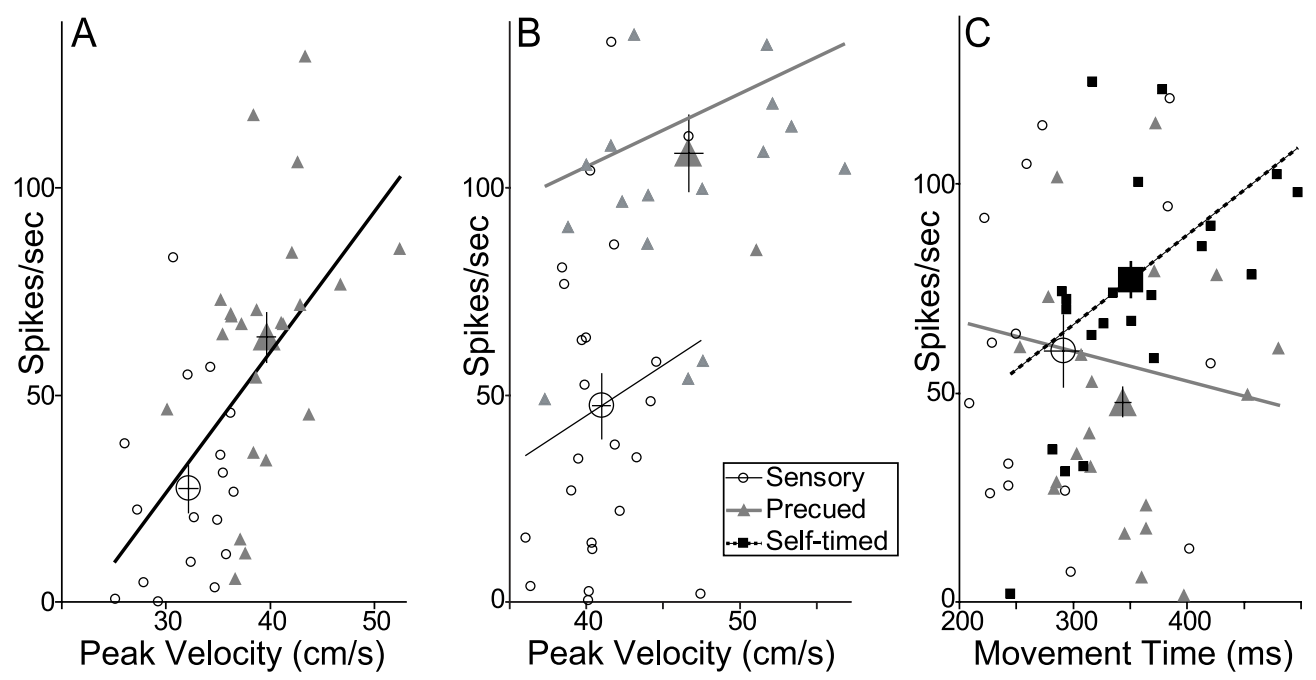

Figure 6. Examples of the interacting effects on perimovement discharge of behavioral condition and parameters of task performance. Single-trial measures of neuronal discharge are plotted versus a performance parameter for movements to one target under sensory, precued, and self-timed conditions $(\bigcirc, \mathbf{\Delta}$, and $\mathbf{\square}$, respectively). Large symbols, Means ( \pm SEM) for respective conditions. $\boldsymbol{A}, 0$ ne of the three cases in which a parametric relationship to task performance accounted for the condition-related difference in discharge is shown. A significant relationship to peak velocity (solid regression line; $p<0.05$; main effect of velocity; ANCOVA) was consistent across sensory and precued conditions ( $p>0.1$ and 0.5 for condition-related differences in $y$-intercept or slope, respectively). Higher velocities under the precued condition ( $p<0.02 ; t$ test) were accompanied by increased discharge rates ( $p<0.05 ; t$ test). (Self-timed condition was not presented.) $B$, An example of a consistent relationship between firing rate and velocity ( $p>0.1$; condition $\times$ velocity interaction; ANCOVA), independent of a strong influence of condition on mean discharge rate ( $p<0.0001$; condition main effect; ANCOVA), is shown. $C$, An example of a condition-dependent parametric relationship is shown. A significant relationship to movement time was present under the self-timed condition only ( $p<0.01$; condition $\times$ velocity interaction; ANCOVA; $p<0.003 ; t$ test for self-timed slope; $p>0.05$ for sensory and precued slopes). Separate regression lines are plotted for the self-timed (dashed) and sensory and precued conditions combined (gray).

\section{Context selectively alters the relationships of pallidal discharge to parameters of task performance}

In light of the pervasive effects of behavioral context on pallidal discharge, how reliably do neurons in the pallidal motor circuit encode parameters of task performance? Although this question is of critical importance for clarifying the possible contributions of pallidal discharge to motor control, there has been a substantial divergence of views on the topic (Georgopoulos et al., 1983; Brotchie et al., 1991a; Mink and Thach, 1991b; Turner and Anderson, 1997; Gdowski et al., 2001). In the current dataset, this question could be addressed most thoroughly for movement direction. Direction varied substantially across trials, being explicitly manipulated by the task, and the discharge of all neurons in the database varied significantly with this parameter.

Influences of behavioral condition on the encoding of movement direction of a neuron were investigated by comparing the fraction of variance in neuronal discharge (across directions and conditions; see Materials and Methods for details) accounted for by three different models. Examples of perimovement discharge well explained by the additive effects, directional gain, and directional shift models are shown in Figure 7, $A, C$, and $E$, respectively. Across the population of responses, the greatest fraction of variance was accounted for by a combination of the first two models: (1) a global alteration of response magnitude independent of direction (i.e., a main effect of condition in the conditionby-direction ANOVA; median 49\% variance explained) (Fig. 7B) and (2) modulations in the gain of a common directional tuning curve (i.e., of constant preferred direction; median $21 \%$ of variance explained) (Fig. 7D). The third model, condition-related alterations in the preferred direction of a neuron, accounted for very little of the condition-by-direction variance in most cells (median 5\% of variance explained) (Fig. $7 F$ ). The first two models combined accounted for a mean $74 \%$ of the variance across behavioral conditions and direction (SD, $\pm 26 \%$ ). Results from this analysis were similar for decreases and increases in discharge
(72 and $78 \%$ of total variance accounted for; $p>0.5 ; t$ test) and for cells from internal and external pallidal segments (both $74 \%$ of total variance accounted for) (Fig. $7 B, D, F$, black and gray shading, respectively).

The influence of behavioral condition on the encoding of other aspects of task performance was investigated using ANCOVA. Because of the low trial-to-trial variability in most measures of task performance, only a limited sample of pallidal responses was found to be correlated with RT, MT, PkVel, or SPHT (Table 2, any effect of factor). Perimovement discharge was correlated with MT and peak velocity in $15 \%$ of the cases tested each ( 13 of 87 cases) (Table 2) $(p<0.05$ for main effect of task factor or condition-by-factor interaction; ANCOVA). Among the cases in which a significant correlation was found, the slope of the relationship was consistent across conditions $50 \%$ of the time (e.g., in 6 of 13 cases for peak velocity; significant main effects of condition and task with no significant interaction) (Table 2). Figure $6 B$ shows an example in which monotonic scaling of firing rate with peak velocity was consistent across sensory and precued conditions (i.e., the slopes did not differ; see figure legend for statistics), despite a substantial influence of behavioral condition on the overall firing rate of the neuron. For the remaining $50 \%$ of cases, the relationship between discharge and task performance differed between conditions. Figure $6 C$ shows an example of perimovement discharge that was correlated with MT only under the self-timed condition, resulting in a significant condition-by-factor interaction in the ANCOVA (statistics in figure legend). The prevalence of factor main effects and of condition-by-factor interactions did not differ between decreases and increases in firing nor between the two pallidal segments ( $\chi^{2}<2.0 ; p>0.2$ for all comparisons).

To summarize, the effects of behavioral condition on the encoding of movement direction were composed primarily of alterations in the overall magnitude of the movement-related discharge of a cell, independent of direction, and of alterations in the 

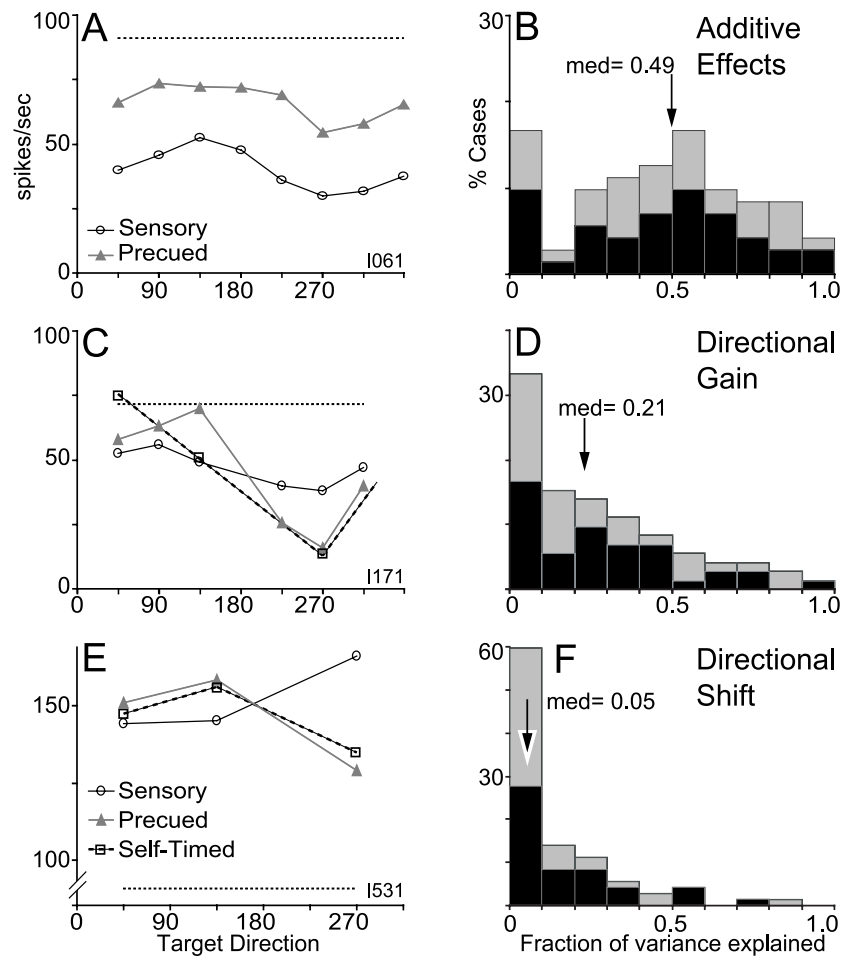

Figure 7. Effects of behavioral condition on the directionality of pallidal discharge. $A, C, E$, Discharge of individual cells that closely fit each of the three regression models. Mean perimovement firing rates are plotted for each condition and direction of movement studied. (Not all directions and conditions were sampled for each cell. See Materials and Methods for details.) $\boldsymbol{A}$, Additive effects of condition and target direction are shown. A perimovement decrease had similar directional tuning under sensory and precued conditions despite greater reductions in firing, overall, under the sensory condition. The additive effects model accounted for $97 \%$ of the differences between conditions in the mean activity of this cell. $\boldsymbol{C}$, An example of alterations in directional gain is shown. The modulation in firing across directions was greater for precued and self-timed conditions compared with the sensory condition, but preferred directions did not differ between conditions $\left(\sim 270^{\circ}\right)$. The directional gain model accounted for $68 \%$ of the direction-by-condition variance. $\boldsymbol{E}$, The best example of a condition-related change in preferred direction is shown. Preferred directions shifted from $270^{\circ}$ for the sensory condition to $125^{\circ}$ for precued and self-timed conditions. The directional shift model accounted for $86 \%$ of the variance across directions and conditions. Horizontal dotted lines, Baseline discharge rate. $\boldsymbol{B}, \boldsymbol{D}, \boldsymbol{F}$, Distributions of the variances explained by additive effects, directional gain, and directional shift models, respectively, for all perimovement activity affected by direction and condition $(n=72$ ) are shown. $\boldsymbol{B}$, The additive effects model accounted for the greatest fraction (median, $49 \%$ ) of the total variance across directions and conditions in most cells. $D$, Changes in the gain of directional discharge of a cell (directional gain model) accounted for a smaller fraction of variance across the population (median, 21\%). $\boldsymbol{F}$, Changes in preferred direction (directional shift model) accounted for very little variance (median, 5\%) across the population. Vertical arrows, Medians of distribution. Gray and black shading of columns indicates distributions for data sampled from GPe and GPi, respectively. med, Median.

magnitude of the directional modulation of the cell. Behavioral condition seldom altered the preferred directions of pallidal discharge, consistent with previous observations (Turner and Anderson, 1997). Within the limited number of cases in which pallidal discharge was correlated with other parameters of task performance, that relationship remained constant across behavioral conditions $50 \%$ of the time.

\section{Recording locations}

It is important to consider the possibility that neurons with different context preferences had different anatomical distributions in the two pallidal segments. A spatial segregation of different response types might be predicted from the anatomical evidence that functionally distinct cortico-basal ganglia circuits occupy different territories in both pallidal segments (Nambu et al., 1990; Hoover and Strick, 1993; Haber, 2003). To address this question, we plotted the approximate anatomical locations of all neurons studied in the two monkeys relative to the pallidal boundaries (Fig. 8). There was no clear segregation of different condition preferences for either decreases (Fig. $8 A$ ) or increases in firing (Fig. $8 B$ ). There also was no clear difference in the distributions of neurons with task-related decreases or increases in firing.

\section{Discussion}

Our study of pallidal activity during reaching under sensory- and memory-contingent conditions yielded the following three principal findings:

(1) Perimovement activity in the skeletomotor region of the globus pallidus was frequently influenced by the memory context of the movement task. The effects of context were equally common between pallidal segments and between increases and decreases in firing. Across the population of neurons as a whole, no preference for a specific context was detected.

(2) Increases and decreases in discharge preferred different memory contexts. Decreases were of greater magnitude under the two sensory-triggered conditions (sensory or precued conditions), whereas increases tended to be larger under memorycontingent conditions (i.e., precued or self-timed conditions). The enhancement of decreases could not be described as sensory responses per se, but rather as an increase in movement-linked activity when movements were sensory triggered. The memorycontingent enhancement of increases was not correlated with preparatory or anticipatory processes but might be related to the control of movement under memory-contingent conditions.

(3) The effects of memory context seldom altered the basic directionality (i.e., preferred direction) of pallidal discharge. Memory context also did not alter the relationships of pallidal discharge to other aspects of task performance (RT, MT, velocity, hold time) in one-half of the cases in which such are a relationship was detected.

These results confirm that memory context has an important influence on the movement-related activity of the BG skeletomotor circuit.

The tasks used here were designed to hold constant aspects of task performance considered irrelevant to the planned comparisons. The aspects of motor performance that did differ between conditions seldom accounted for context-related differences in discharge ( $3 \%$ of cases). Although pairs of conditions shared more than one potential explanatory factors, secondary analyses discriminated between these alternatives (see below, Functional significance). Because the BG are composed of multiple functionally distinct circuits (Middleton and Strick, 2000), it is important to consider whether a homogeneous population of neurons was studied. Our data were sampled from the skeletomotor arm region of the pallidum based on the location of recordings in the posterior lateral pallidum (Turner and Anderson, 1997), the presence of discharge time-locked to movement initiation and modulated by movement direction, and the presence of responses to proprioceptive stimulation of the proximal arm. Note that the present results concerning reach-related activity in the skeletomotor circuit do not preclude the associative and limbic functions proposed for other BG regions (Middleton and Strick, 2000; Haber, 2003).

\section{Comparison with previous results}

Our results agree with previous reports that perimovement pallidal activity differs depending on movement context (Brotchie et 
al., 1991a,b; Mink and Thach, 1991b; Mushiake and Strick, 1995; Gdowski et al., 2001). Our new finding, that increases and decreases prefer different contexts, may explain the divergent views on whether pallidal activity shows a preference for memory- or sensory-contingent conditions. Substantial attention has been given to Hikosaka and Wurtz's (1983b) observation of memory-contingent saccaderelated activity in the substantia nigra reticulata. It is worth noting, however, that the same authors described sensorycontingent activity in a similar fraction of the neurons studied (Hikosaka and Wurtz, 1983a). Mink and Thach (1991a) found that pallidal activity related to wrist movement also differed depending on movement context, but no consistent relationship was found for one mode of movement. van Donkelaar et al. (1999) concluded that the BG-thalamocortical circuit preferentially encodes self-timed movements, a view also supported by a recent functional imaging study (Taniwaki et al., 2003). In contrast, Gdowski et al. (2001) found that pallidal activity was enhanced for movements that were sensorytriggered and rewarded. Thus, previous studies clearly demonstrate that pallidal activity differs depending on the mode of movement, but they provide no consensus on what aspect(s) of cognitive motor control might be particularly relevant. Our results are the first to demonstrate strong context preferences in pallidal discharge that differ between increases and decreases in discharge.

The minimal difference in results from the two pallidal segments is consistent with previous studies showing that taskrelated activity in the two pallidal segments is similar in almost every respect (Mitchell et al., 1987; Hamada et al., 1990; Mink and Thach, 1991a,b; Turner and Anderson, 1997). The consistent similarity makes it unlikely that linked external and internal pallidal cells have strictly reciprocal firing patterns as is hypothesized in standard models of BG "direct" and "indirect" pathways (Albin et al., 1989; DeLong, 1990).

\section{Potential mechanisms for the context preferences of decreases and increases}

Current knowledge of BG circuitry offers tentative candidates for the pathways that mediate the current results. A strong constraint is the similarity of results from GPe and GPi, implying dependence on pathways that innervate GPe and GPi similarly. The most obvious inhibitory input to both pallidal segments comes from the medium spiny neurons of the striatum (Kimura et al., 1996). Separate populations of striatal neurons innervate GPe alone and GPe and GPi (Gerfen and Wilson, 1996; Wu et al., 2000), but there is no indication that different task information is encoded in these two populations. Neurons in the striatal motor circuit respond to salient sensory and motor events with phasic bursts of activity. Although individual medium spiny neurons have been reported to prefer sensory- or memory-contingent conditions, no systematic bias has been found for one movement mode (Kimura et al., 1992). Sensory-triggered enhancement of pallidal decreases may be a product of a distinct class of striatal projection neurons, such as the individual medium spiny neurons reported to be phasically active preceding the first of three sequential movements [type IIa (Kimura et al., 1996)].

The subthalamic nucleus (STN) is the most likely source of pallidal increases and their enhancement under memorycontingent conditions. STN provides the dominant excitatory input to both pallidal segments (Hazrati and Parent, 1992), and the primary determinants of STN firing are excitatory inputs from frontal cortex (Nambu et al., 2002) and thalamus (Orieux et al., 2000). The movement-related activity of STN neurons has not been studied extensively in nonparkinsonian subjects (Wichmann et al., 1994), particularly with respect to potential preferences for memory-contingent conditions. Patient studies, however, suggest the STN is activated selectively under memorycontingent conditions (Paradiso et al., 2003; Williams et al., 2003). Other mechanisms that could contribute to increases in pallidal firing include rebound excitation (Nambu and Llinas, 1994) and excitatory input from the midbrain tegmentum (Gonya-Magee and Anderson, 1983).

\section{Functional significance}

The observation that context preferences differed for increases and decreases in firing has great potential significance. The results for GPi neurons are especially important because these neurons 
constitute the primary output pathway by which the BG influences skeletomotor centers. Decreases and increases in GPi firing facilitate and suppress activity in those centers, respectively, through GABAergic action on thalamocortical circuits (DeVito and Anderson, 1982; Albin et al., 1989). The results from GPe neurons are more difficult to infer because the net effects of GPe discharge on downstream targets are poorly understood (for two views, see Parent and Hazrati, 1995; Gurney et al., 2001). Our observation of similar encoding of task information in the two pallidal segments runs contrary to a commonly held view that linked GPe and GPi neurons should have reciprocally related firing patterns (Albin et al., 1989; DeLong, 1990).

Perimovement decreases were enhanced under sensorytriggered conditions. We found scant evidence that these responses were linked temporally to the trigger stimulus itself, but more than one-half were linked to movement initiation, suggesting that decreases were preferentially related to some aspect of the execution of sensory-triggered movement. It is unlikely these signals play a role in movement initiation per se, because movement-related activity in the BG seldom begins before agonist muscle activation (Crutcher and Alexander, 1990; Mink and Thach, 1991b; Turner and Anderson, 1997), and because GPi inactivation seldom impairs movement initiation (Horak and Anderson, 1984a; Mink and Thach, 1991a; Inase et al., 1996). These pallidal signals may contribute, however, to the online control of movement, including the development of movement amplitude and/or peak velocity (Anderson and Horak, 1985; Turner and Anderson, 1997). These results are in apparent conflict with a well recognized hypothesis that the BG-thalamocortical circuit contributes preferentially to the control of selfinitiated movements (Benecke et al., 1987b; Romo et al., 1992; van Donkelaar et al., 1999, 2000; Cunnington et al., 2002; Taniwaki et al., 2003). The results for GPi indicate that movementselecting or -facilitatory signals exiting the BG are in fact less prevalent under self-initiated conditions. Although this specific discrepancy requires additional investigation, the general topic of BG involvement in memory-contingent control is revisited below.

Pallidal increases were enhanced most often for movements performed in the absence of immediate sensory cues. These enhancements were not correlated with preparatory or anticipatory processes present before movement initiation. Increases in GPi firing are thought to suppress activity in thalamocortical circuits. Several groups have proposed that GPi increases produce a surround-inhibition effect, suppressing thalamocortical activity that would otherwise interfere with efficient, automatic production of movement (Mink, 1996; Redgrave et al., 1999). Why would the BG generate greater suppression when movements are performed in the absence of immediate sensory information? There is good evidence that suppression of frontal cortical activity is mediated by multiple mechanisms (Rubia et al., 2001; Eimer and Schlaghecken, 2003), including sensory inputs when available (Chen et al., 1999; Schlaghecken and Eimer, 2002). The BG may play a flexible role that can "stand in" for the suppressing effects of sensory inputs when they are absent. Thus, the suppressing functions of BG output may increase in importance the more the immediate sensory environment fails to define the demands of a task. Disruption of this focusing function may underlie the greater impact of BG dysfunction on self-guided and selfinitiated movement (Benecke et al., 1987a; Praamstra et al., 1998).

\section{References}

Adamovich SV, Berkinblit MB, Hening W, Sage J, Poizner H (2001) The interaction of visual and proprioceptive inputs in pointing to actual and remembered targets in Parkinson's disease. Neuroscience 104:1027-1041.

Albin RL, Young AB, Penney JB (1989) The functional anatomy of basal ganglia disorders. Trends Neurosci 12:366-375.

Anderson ME, Horak FB (1985) Influence of the globus pallidus on arm movements in monkeys. III. Timing of movement-related information. J Neurophysiol 54:433-448.

Anderson ME, Turner RS (1991) A quantitative analysis of pallidal discharge during targeted reaching movement in the monkey. Exp Brain Res 86:623-632.

Benecke R, Rothwell JC, Dick JPR, Day BL, Marsden CD (1987a) Simple and complex movements off and on treatment in patients with Parkinson's disease. J Neurol Neurosurg Psychiatry 50:296-303.

Benecke R, Rothwell JC, Dick JPR, Day BL, Marsden CD (1987b) Disturbances of sequential movements in patients with Parkinson's disease. Brain 110:361-379.

Brotchie P, Iansek R, Horne MK (1991a) Motor function of the monkey globus pallidus. 1. Neuronal discharge and parameters of movement. Brain 114:1667-1683.

Brotchie P, Iansek R, Horne MK (1991b) Motor function of the monkey globus pallidus. 2. Cognitive aspects of movement and phasic neuronal activity. Brain 114:1685-1702.

Chen R, Corwell B, Hallett M (1999) Modulation of motor cortex excitability by median nerve and digit stimulation. Exp Brain Res 129:77-86.

Commenges D, Seal J (1985) The analysis of neuronal discharge sequences: change-point estimation and comparison of variances. Stat Med 4:91-104.

Crutcher MD, Alexander GE (1990) Movement-related neuronal activity selectively coding either direction or muscle pattern in three motor areas of the monkey. J Neurophysiol 64:151-163.

Cunnington R, Windischberger C, Deecke L, Moser E (2002) The preparation and execution of self-initiated and externally-triggered movement: a study of event-related fMRI. NeuroImage 15:373-385.

DeLong MR (1990) Primate models of movement disorders of basal ganglia origin. Trends Neurosci 13:281-285.

DeVito JL, Anderson ME (1982) An autoradiographic study of the efferent connections of the globus pallidus in Macaca mullata. Brain Res 46:107-117.

Eimer M, Schlaghecken F (2003) Response facilitation and inhibition in subliminal priming. Biol Psychol 64:7-26.

Fisher NI (1993) Statistical analysis of circular data. Cambridge, UK: Cambridge UP.

Gdowski MJ, Miller LE, Parrish T, Nenonene EK, Houk JC (2001) Context dependency in the globus pallidus internal segment during targeted arm movements. J Neurophysiol 85:998-1004.

Georgopoulos A, Kalaska J, Caminiti R, Massey J (1982) On the relations between the direction of two-dimensional arm movements and cell discharge in primate motor cortex. J Neurosci 2:1527-1537.

Georgopoulos A, DeLong M, Crutcher M (1983) Relations between parameters of step-tracking movements and single cell discharge in the globus pallidus and subthalamic nucleus of the behaving monkey. J Neurosci 3:1586-1598.

Gerfen CR, Wilson CJ (1996) The basal ganglia. In: Handbook of chemical neuroanatomy (Swanson LW, Björklund A, Hökfelt T, eds), pp 371-468. New York: Elsevier.

Goldberg G (1985) Supplementary motor area structure and function: review and hypotheses. Behav Brain Sci 8:567-616.

Gonya-Magee T, Anderson ME (1983) An electrophysiological characterization of projections from the pedunculopontine area to entopeduncular nucleus and globus pallidus in the cat. Exp Brain Res 49:269-279.

Gurney K, Prescott TJ, Redgrave P (2001) A computational model of action selection in the basal ganglia. II. Analysis and simulation of behaviour. Biol Cybern 84:411-423.

Haber SN (2003) The primate basal ganglia: parallel and integrative networks. J Chem Neuroanat 26:317-330.

Hamada I, DeLong MR, Mano N (1990) Activity of identified wrist-related pallidal neurons during step and ramp wrist movements in the monkey. J Neurophysiol 64:1892-1906.

Hanes DP, Thompson KG, Schall JD (1995) Relationship of presaccadic 
activity in frontal eye field and supplementary eye field to saccade initiation in macaque: Poisson spike train analysis. Exp Brain Res 103:85-96.

Hazrati LN, Parent A (1992) Differential patterns of arborization of striatal and subthalamic fibers in the two pallidal segments in primates. Brain Res 598:311-315.

Hikosaka O, Wurtz RH (1983a) Visual and oculomotor functions of monkey substantia nigra pars reticulata. I. Relation of visual and auditory responses to saccades. J Neurophysiol 49:1230-1253.

Hikosaka O, Wurtz RH (1983b) Visual and oculomotor functions of monkey substantia nigra pars reticulata. III. Memory-contingent visual and saccade responses. J Neurophysiol 49:1268-1284.

Hikosaka O, Wurtz RH (1985) Modification of saccadic eye movements by GABA-related substances. II. Effects of muscimol in monkey substantia nigra pars reticulata. J Neurophysiol 53:292-308.

Hoover JE, Strick PL (1993) Multiple output channels in the basal ganglia. Science 259:819-821.

Horak FB, Anderson ME (1984a) Influence of globus pallidus on arm movements in monkeys. I. Effects of kainic acid-induced lesions. J Neurophysiol 52:290-304.

Horak FB, Anderson ME (1984b) Influence of globus pallidus on arm movements in monkeys. II. Effects of stimulation. J Neurophysiol 52:305-322.

Inase M, Buford JA, Anderson ME (1996) Changes in the control of arm position, movement, and thalamic discharge during local inactivation in the globus pallidus of the monkey. J Neurophysiol 75:1087-1104.

Johnson RA, Wichern DW (1982) Applied multivariate statistical analysis. Englewood Cliffs, NJ: Prentice Hall.

Kimura M, Aosaki T, Hu Y, Ishida A, Watanabe K (1992) Activity of primate putamen neurons is selective to the mode of voluntary movement: visually guided, self-initiated or memory-guided. Exp Brain Res 89:473-477.

Kimura M, Kato M, Shimazaki H, Watanabe K, Matsumoto N (1996) Neural information transferred from the putamen to the globus pallidus during learned movement in the monkey. J Neurophysiol 76:3771-3786.

Leamer EE (1987) Paths of development in the three-factor, n-good general equilibrium model. J Polit Econ 95:961-999.

Lurito JT, Georgakopoulos T, Georgopoulos AP (1991) Cognitive spatialmotor processes. 7. The making of movements at an angle from a stimulus direction: studies of motor cortical activity at the single cell and population levels. Exp Brain Res 87:562-580.

Mardia KV (1972) Statistics of directional data. New York: Academic.

Middleton FA, Strick PL (2000) Basal ganglia and cerebellar loops: motor and cognitive circuits. Brain Res Brain Res Rev 31:236-250.

Mink J (1996) The basal ganglia: focused selection and inhibition of competing motor programs. Prog Neurobiol 50:381-425.

Mink J, Thach W (1991a) Basal ganglia motor control. I. Nonexclusive relation of pallidal discharge to five movement modes. J Neurophysiol 65:273-300

Mink J, Thach W (1991b) Basal ganglia motor control. II. Late pallidal timing relative to movement onset and inconsistent pallidal coding of movement parameters. J Neurophysiol 65:301-329.

Mink J, Thach W (1991c) Basal ganglia motor control. III. Pallidal ablation: normal reaction time, muscle cocontraction, and slow movement. J Neurophysiol 65:330-351.

Mitchell SJ, Richardson RT, Baker FH, DeLong MR (1987) The primate globus pallidus: neuronal activity related to direction of movement. Exp Brain Res 68:491-505.

Mushiake H, Strick PL (1995) Pallidal neuron activity during sequential arm movements. J Neurophysiol 74:2754-2758.

Nambu A, Llinas R (1994) Electrophysiology of globus pallidus neurons in vitro. J Neurophysiol 72:1127-1139.

Nambu A, Yoshida S, Jinnai K (1990) Discharge patterns of pallidal neurons with input from various cortical areas during movement in the monkey. Brain Res 519:183-191.

Nambu A, Tokuno H, Takada M (2002) Functional significance of the cortico-subthalamo-pallidal "hyperdirect" pathway. Neurosci Res 43:111-117.

Orieux G, Francois C, Feger J, Yelnik J, Vila M, Ruberg M, Agid Y, Hirsch EC (2000) Metabolic activity of excitatory parafascicular and pedunculopontine inputs to the subthalamic nucleus in a rat model of Parkinson's disease. Neuroscience 97:79-88.

Paradiso G, Saint-Cyr JA, Lozano AM, Lang AE, Chen R (2003) Involvement of the human subthalamic nucleus in movement preparation. Neurology 61:1538-1545.

Parent A, Hazrati LN (1995) Functional anatomy of the basal ganglia. II. The place of subthalamic nucleus and external pallidum in basal ganglia circuitry. Brain Res Brain Res Rev 20:128-154.

Praamstra P, Stegeman DF, Cools AR, Horstink MW (1998) Reliance on external cues for movement initiation in Parkinson's disease. Evidence from movement-related potentials. Brain 121:167-177.

Redgrave P, Prescott TJ, Gurney K (1999) The basal ganglia: a vertebrate solution to the selection problem? Neuroscience 89:1009-1023.

Romo R, Scarnati E, Schultz W (1992) Role of primate basal ganglia and frontal cortex in the internal generation of movements. II. Movementrelated activity in the anterior striatum. Exp Brain Res 91:385-395.

Rubia K, Russell T, Overmeyer S, Brammer MJ, Bullmore ET, Sharma T, Simmons A, Williams SC, Giampietro V, Andrew CM, Taylor E (2001) Mapping motor inhibition: conjunctive brain activations across different versions of go/no-go and stop tasks. NeuroImage 13:250-261.

Schlaghecken F, Eimer M (2002) Motor activation with and without inhibition: evidence for a threshold mechanism in motor control. Percept Psychophys 64:148-162.

Szabo J, Cowan WM (1984) A stereotaxic atlas of the brain of the cynomologus monkey. J Comp Neurol 222:265-309.

Szucs A (1998) Applications of the spike density function in analysis of neuronal firing patterns. J Neurosci Methods 81:159-167.

Taniwaki T, Okayama A, Yoshiura T, Nakamura Y, Goto Y, Kira J, Tobimatsu S (2003) Reappraisal of the motor role of basal ganglia: a functional magnetic resonance image study. J Neurosci 23:3432-3438.

Turner RS, Anderson ME (1997) Pallidal discharge related to the kinematics of reaching movements in two dimensions. J Neurophysiol 77:1051-1074.

Turner RS, Owens JWM, Anderson ME (1995) Directional variation of spatial and temporal characteristics of limb movements made by monkeys in a two-dimensional work space. J Neurophysiol 74:684-697.

Turner RS, Desmurget M, Grethe J, Crutcher MD, Grafton ST (2003) Motor subcircuits mediating the control of movement extent and speed. J Neurophysiol 90:3958-3966.

van Donkelaar P, Stein JF, Passingham RE, Miall RC (1999) Neuronal activity in the primate motor thalamus during visually triggered and internally generated limb movements. J Neurophysiol 82:934-945.

van Donkelaar P, Stein JF, Passingham RE, Miall RC (2000) Temporary inactivation in the primate motor thalamus during visually triggered and internally generated limb movements. J Neurophysiol 83:2780-2790.

Wichmann T, Bergman H, DeLong MR (1994) The primate subthalamic nucleus. I. Functional properties in intact animals. J Neurophysiol 72:494-506.

Williams D, Kuhn A, Kupsch A, Tijssen M, van Bruggen G, Speelman H, Hotton G, Yarrow K, Brown P (2003) Behavioural cues are associated with modulations of synchronous oscillations in the human subthalamic nucleus. Brain 126:1975-1985.

Wu Y, Richard S, Parent A (2000) The organization of the striatal output system: a single-cell juxtacellular labeling study in the rat. Neurosci Res $38: 49-62$. 